\title{
Emodin alleviates LPS-induced inflammatory response in lung injury rat by affecting the function of granulocytes
}

\author{
Hongxia Mei ${ }^{1,2}$, Ying Tao ${ }^{2}$, Tianhao Zhang ${ }^{2}$ and Feng Qi ${ }^{1 *}$ (D)
}

\begin{abstract}
Background: Acute lung injury (ALI) and/or acute respiratory distress syndrome (ARDS) are critical life-threatening syndromes characterized by the infiltration of a large number of granulocytes (mainly neutrophils) that lead to an excessive inflammatory response. Emodin (Emo) is a naturally occurring anthraquinone derivative and an active ingredient of Chinese medicine. It is believed to have anti-inflammatory effects. In this study, we examined the impact of Emo on the pulmonary inflammatory response and the granulocytes function in a rat model of lipopolysaccharide (LPS)-induced ALI.

Results: Treatment with Emo protected rat against LPS-induced ALI. Compared to untreated rat, Emo-treated rat exhibited significantly ameliorated lung pathological changes and decreased tumor necrosis factor-a (TNF-a) and interleukin-1 $\beta$ (IL-1 $\beta$ ). However, Emo has no protective effect on the rat model of acute lung injury with granulocyte deficiency. In addition, treatment with Emo enhanced the bactericidal capacity of LPS-induced granulocytes via the up-regulation of the ability of granulocytes to phagocytize bacteria and generate neutrophil extracellular traps (NETs). Emo also downregulated the respiratory burst and the expression of reactive oxygen species (ROS) in LPS-stimulated granulocytes, alleviating the damage of granulocytes to surrounding tissues. Finally, Emo can accelerate the resolution of inflammation by promoting apoptosis of granulocytes.
\end{abstract}

Conclusion: Our results provide the evidence that Emo could ameliorates LPS-induced ALI via its anti-inflammatory action by modulating the function of granulocytes. Emo may be a promising preventive and therapeutic agent in the treatment of ALI.

Keywords: Emodin, Granulocytes, Acute lung injury (ALI), Acute respiratory distress syndrome (ARDS)

\section{Background}

Acute lung injury (ALI) and its more severe form, acute respiratory distress syndrome (ARDS), are devastating clinical syndromes. Bacterial or viral pneumonia and sepsis are the most common causes of ALI and ARDS, wherein Gram-negative bacteria are a prominent cause [1]. Lipopolysaccharide (LPS), an important component of the outer membrane of Gram-negative bacteria, is

\footnotetext{
* Correspondence: qifeng66821@sina.com

'Department of Anesthesiology, Qilu Hospital, Cheeloo College of Medicine, Shandong University, Jinan 250012, Shandong Province, China

Full list of author information is available at the end of the article
}

one of the main pro-inflammatory reaction factors in ALI and leads to neutrophil recruitment and pulmonary edema [2, 3].

Granulocytes are the most abundant white blood cells, including neutrophils, eosinophils and basophils, most of which are neutrophils. They are essential for killing bacteria and other microorganisms, and they also have a significant role in regulating the inflammatory response. In order to exert its bactericidal function, circulating granulocytes first follow the chemokine gradient to the inflammatory site. They kill the pathogenic microorganisms through mechanisms, such as phagocytosis, 
secretion of germicidal particles and neutrophil extracellular traps (NETs).

Granulocyte migration through the activated venous wall is a prerequisite for granulocytes entry to interstitial infection injury and emergency sites [4]. The local hydrolysis of JAM-C proteins on vascular endothelial cells by elastase is a necessary factor for granulocytes to pass through the vein wall [5]. One of the hallmarks associated with the antimicrobial and inflammatory actions of granulocytes is the activation of a powerful respiratory burst, during which granulocytes produce and release large quantities of antibacterial peptides, proteases, and reactive oxygen species (ROS) to kill pathogens entrapped inside the vacuole. The phagocyte NADPH oxidase activity and ROS production play a key role in host defense against microbial pathogens [6].

In response to specific stimuli, neutrophils, the main components of granulocytes, extrude modified chromatin structures decorated with specific cytoplasmic and granular proteins called NETs [7]. NETs is a special form of bactericidal method for neutrophils [8]. The engulfment of apoptotic cells by phagocytes is essential for maintaining normal tissue homeostasis and a prerequisite for the resolution of inflammation [9]. The removal of apoptotic granulocytes from circulation regulates granulopoiesis, and prevents secondary lysis and spillage of noxious granulocyte substances $[10,11]$.

Rhubarb is one of the most commonly used herbs in traditional Chinese medicine. Emodin (Emo) is mainly extracted from rhizome and root of rhubarb. Its chemical name is 1,3,8-trihydroxy-6-methyl-anthraquinone, and its molecular weight is 270.23 . Its chemical structure belongs to the hydroxyindole family. In recent years, studies have found that Emo has a wide range of pharmacological effects, mainly anti-tumor, anti-microbial, anti-oxidation, and anti-inflammatory [12-15]. Modern researches show that Emo extract could significantly inhibit the inflammatory responses in a variety of inflammatory animal models [16]. This is achieved by directly or indirectly inhibiting the activity of inflammatory cells. Currently, the study of Emo on inflammatory cells is mainly focused on macrophages. Its modulation effects on other immune cells, such as granulocytes which play a very important role in lung inflammation-related disease, are not fully elucidated.

This study was designed to investigate whether Emo could exert protective effects on LPS-induced ALI in vivo and whether Emo plays a protective role by affecting the function of granulocytes. In addition, we investigated the effect of different doses of Emo on the function of granulocytes in vitro.

\section{Results}

Effects of Emo on the proliferation of rat granulocytes

As shown in Fig. 1a, the structure of Emo shows that it belongs to the terpenoid family. Pure rat granulocytes can be obtained by gradient centrifugation as mentioned above. Figure $1 \mathrm{~b}$ shows rat granulocytes after immunofluorescence staining. Red is granulocyte MPO and blue is granulocyte lobulated nucleus. The ratio of rat granulocytes was quantified, and the purity could reach $94.1 \%$ of the isolated cells. Subsequently, different concentrations of Emo were administrated to the granulocytes for $4 \mathrm{~h}$. As shown in Fig. 1c, Emo at the concentration of $40 \mu \mathrm{M}$ and $80 \mu \mathrm{M}$ had high cytotoxic effect on granulocytes, while the lower concentration of Emo had little cytotoxic effect on granulocytes. EMO of $5 \mu \mathrm{M}, 10 \mu \mathrm{M}$ and $20 \mu \mathrm{M}$ was selected for further study.

\section{Emo protected lung tissues from LPS-induced ALI}

First, we evaluated the effect of Emo on LPS-induced ALI. The control group revealed normal pulmonary histology (Fig. 2a). In contrast, lung tissues in the LPS group were significantly damaged, with interstitial edema, hemorrhaging, thickening of the alveolar wall, and infiltration of inflammatory cells into the interstitium and alveolar spaces, as evidenced by an increase in lung injury score $(p<0.01)$. Compared with the control group, all the morphologic changes observed were less pronounced in the LPS + Emo $5 \mathrm{mg} / \mathrm{kg}$ group, LPS + Emo $10 \mathrm{mg} / \mathrm{kg}$ group and LPS + Emo $20 \mathrm{mg} / \mathrm{kg}$ group. Emo 5 $\mathrm{mg} / \mathrm{kg}$ attenuated LPS-induced pathologic changes as shown by the decrease in lung injury score $(p<0.05)$. As Emo dosage was increased, the attenuation of LPSinduced pathologic also increased. $10 \mathrm{mg} / \mathrm{kg}$ and $20 \mathrm{mg} /$ $\mathrm{kg}$ Emo could significantly attenuate LPS-induced pathologic changes $(p<0.01)$ (Fig. 2b).

As expected, the concentrations of TNF- $\alpha$ and IL- $1 \beta$ in the lung tissue homogenate were significantly higher in the LPS group than in the control group. By comparison, the level of TNF in LPS +Emo $5 \mathrm{mg} / \mathrm{kg}$ group, LPS + Emo $10 \mathrm{mg} / \mathrm{kg}$ group and LPS + Emo $20 \mathrm{mg} / \mathrm{kg}$ group decreased in varying degrees, and the decrease of TNF level in LPS + Emo $20 \mathrm{mg} / \mathrm{kg}$ group was the most significant (Fig. 2c). After treatment with Emo $10 \mathrm{mg} / \mathrm{kg}$ and Emo $20 \mathrm{mg} / \mathrm{kg}$, the level of IL-1 in lung homogenate was also decreased, and Emo $20 \mathrm{mg} / \mathrm{kg}$ could significantly reduce the level of IL-1(Fig. 2d).

\section{Emo impact on respiratory burst and ROS production of granulocytes}

As shown in Fig. 3a, the level of $\mathrm{O}_{2}{ }^{-}$in which the LPS group has a very significant boosting effect on the production of neutrophil $\mathrm{O}_{2}{ }^{-}$following fMLP stimulation was detected $(P<0.01)$. Emo decreased the production 
A<smiles>Cc1cc(O)c2c(c1)C(=O)c1cc(O)cc(O)c1C2=O</smiles>

Emodin MW:270.240

C

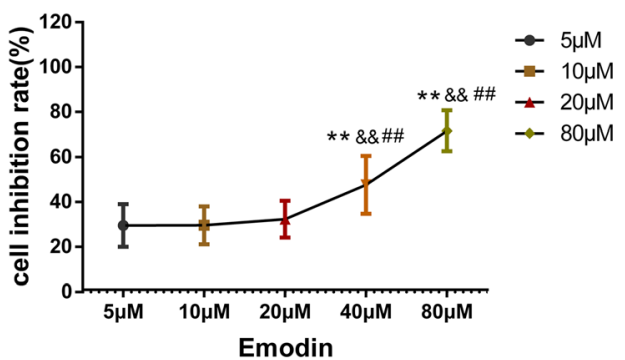

B

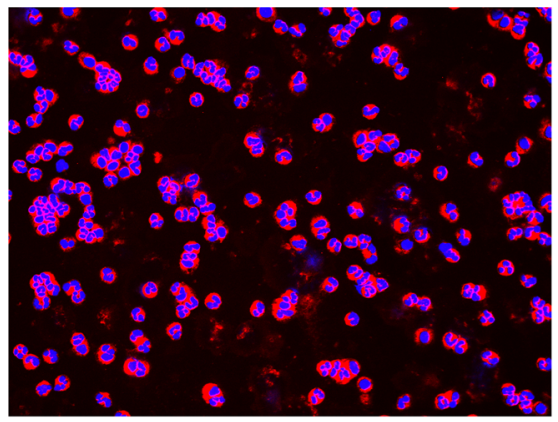

Fig. 1 a Schematic diagram of Emo; b Immunofluorescence staining of rat granulocytes. (C) CCK8 assay. The effect of different concentrations of Emo on granulocytes Cytotoxicity in rats was examined. The data are presented as the mean $\pm \mathrm{SD} . n=6 .{ }^{* *} p<0.01$ versus Emo $5 \mu \mathrm{M}$ group; ${ }^{\&} \&$ $<0.01$ versus Emo $10 \mu \mathrm{M}$ group; ${ }^{\# \#} P<0.01$ versus Emo $20 \mu \mathrm{M}$ group

of $\mathrm{O}_{2}{ }^{-}$in a concentration-dependent manner $(P<0.01)$ (Fig. 3a).

The expression of ROS in granulocytes was measured by Luminometer (Fig. 3b-c). According to the literature, we found that there are four groups of agents that can induce ROS production. The first group of priming agents is composed of physiological inflammatory agents, such as $\mathrm{C} 5 \mathrm{a}$, or formylated peptides/proteins such as fMLP. The second group of priming agents is composed of proinflammatory cytokines and adipokines, such as tumor necrosis factor (TNF- $\alpha$ ), IL-8. The third group of priming agents is composed of TLR agonists, such as lipopolysaccharide (LPS or endotoxin). The four group of priming agents is Phorbol ester (PMA). Therefore, we chose three agents IL-8、 fMLP and PMA to stimulate granulocytes to produce ROS.

It was found that PMA was the best at stimulating granulocytes to produce ROS $(P<0.01)$ (Fig. $3 b)$. Therefore, in the following experiments, PMA was used as an inducer to stimulate granulocytes to produce ROS. Granulocytes were divided into five groups: control group, LPS group (100 ng/ml), LPS + Emo $5 \mu \mathrm{M}$ group, LPS + Emo $10 \mu \mathrm{M}$ group and LPS + Emo $20 \mu \mathrm{M}$ group. Stimulation with Emo was performed for $30 \mathrm{~min}$ prior to LPS treatment. PMA $(1.5 \mathrm{ng} / \mathrm{ml})$ was used to treat the cells respectively. The ROS production of granulocytes was detected according to the above procedure. In this experiment, the concentration of ROS in the LPS group was significantly increased compared with the control group $(P<0.01)$. Compared with the LPS group, $10 \mu \mathrm{M}$
Emo and $20 \mu \mathrm{M}$ Emo reduced ROS production, with $20 \mu \mathrm{M}$ Emo having an even better effect $(P<0.01)$. At $5 \mu \mathrm{M}$, Emo has no effect $(P>0.05)$ (Fig. 3c).

\section{Emo effect on the release of elastase and NETs production of granulocytes}

As shown in Fig. 4a, the amount of elastase released was significantly higher in the LPS group following stimulation with fMLP than in the control group $(P<0.01)$. This indicates that granulocytes increase the release of elastase in order to fight infection. Elastase release in LPS + Emo $10 \mu \mathrm{M}$ and LPS + Emo $20 \mu \mathrm{M}$ groups were significantly higher than control group and LPS group $(P<$ 0.01).

The literature also confirmed that four group of reagents that induce ROS production can also stimulate the production of NETs, so we also choose four agents LPS, IL-8, fMLP and PMA to induce the production of NETs. Our study found that PMA stimulates granulocytes to produce the most NETs compared with IL-8, LPS and fMLP $(P<0.01)$ (Fig. $4 \mathrm{~b})$. As a result, PMA was used as the inducer.

Therefore, in the following experiments, PMA was used as an inducer to stimulate granulocytes to produce NETs. Granulocytes were divided into five groups: control group, LPS group $(100 \mathrm{ng} / \mathrm{ml})$, LPS + Emo $5 \mu \mathrm{M}$ group, LPS + Emo $10 \mu \mathrm{M}$ group and LPS + Emo $20 \mu \mathrm{M}$ group. Stimulation with Emo was performed for $30 \mathrm{~min}$ prior to LPS treatment. PMA $(1.5 \mathrm{ng} / \mathrm{ml})$ was used to treat the cells respectively. The NETs production of 

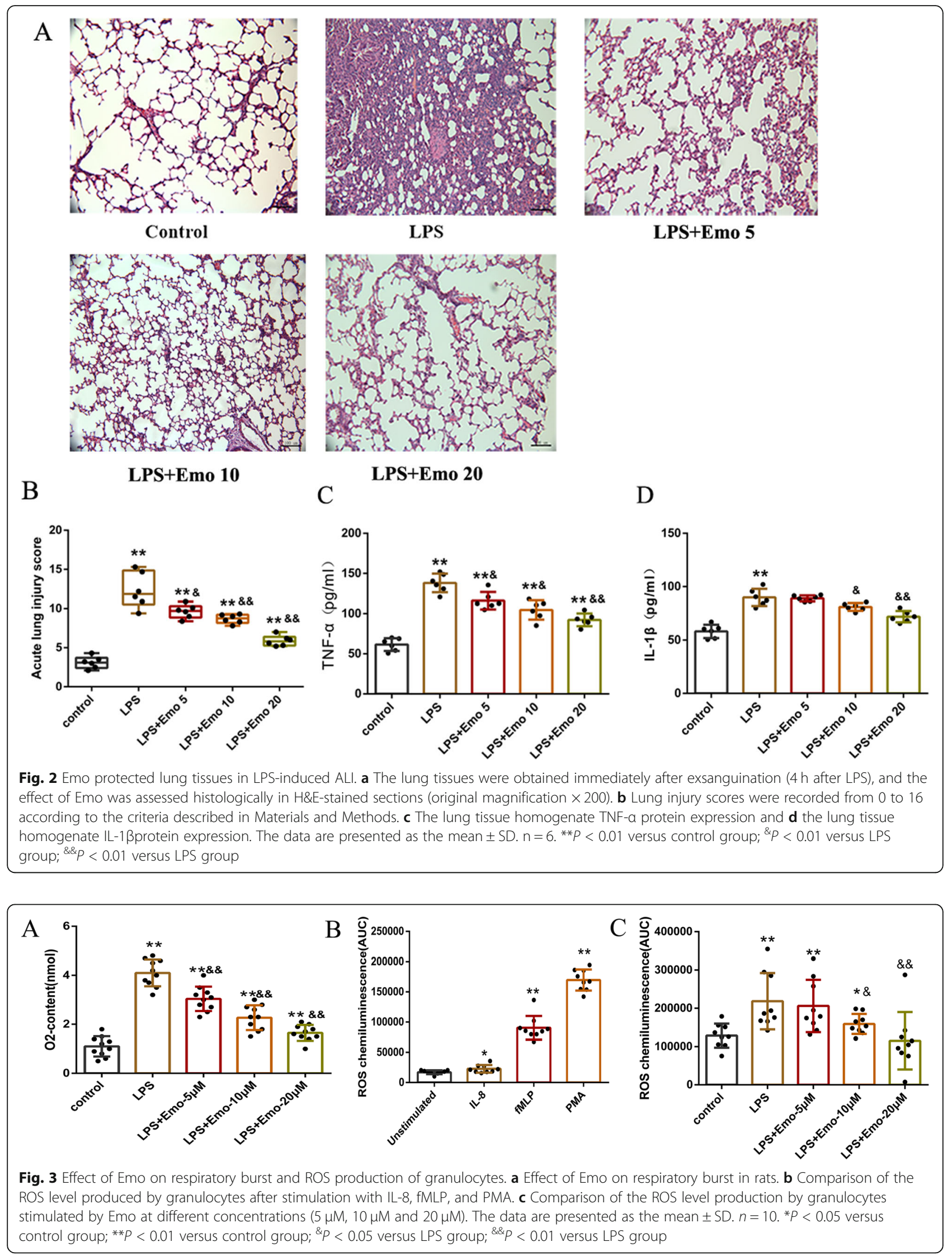


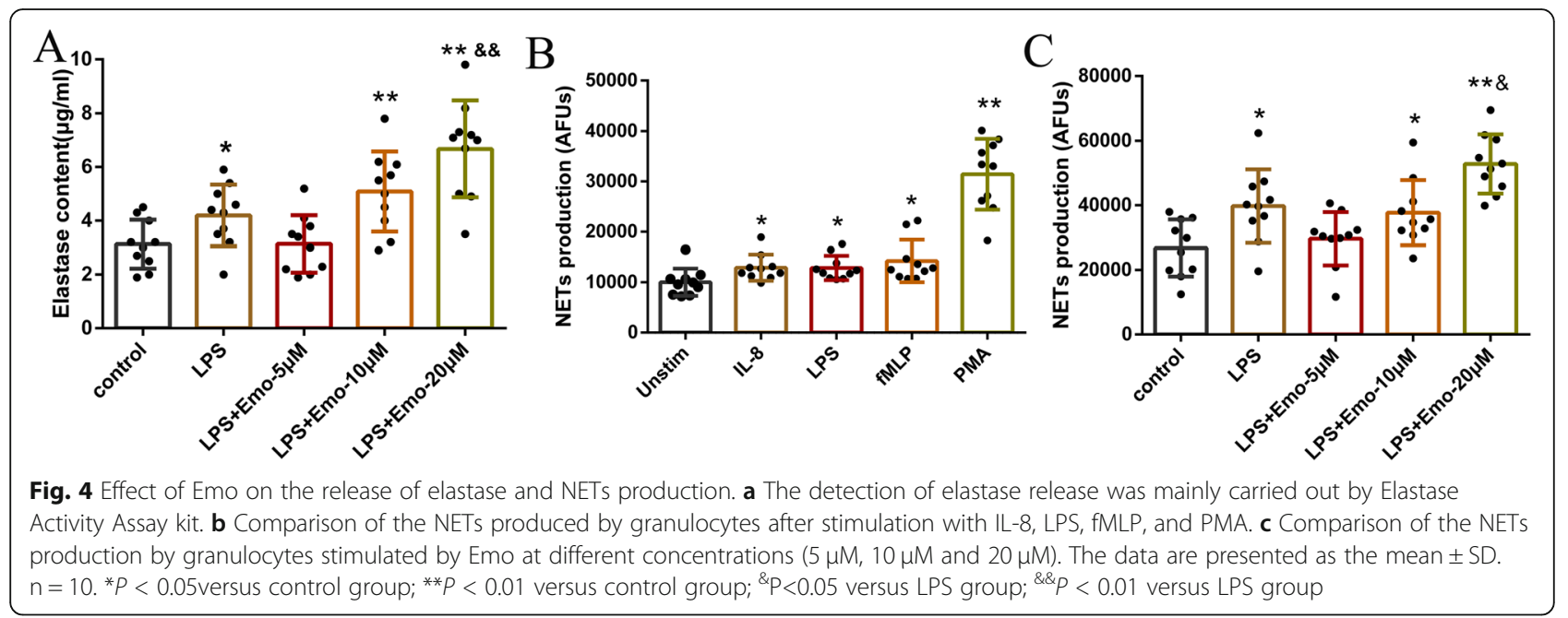

granulocytes was detected according to the above procedure. This study found that after PMA stimulation, the generation of NETs in the LPS group increased significantly compared with the control group $(P<0.05)$. In $5 \mu \mathrm{M}$ Emo and $10 \mu \mathrm{M}$ Emo groups, the generation of NETs did not increase compared with the LPS group. However, $20 \mu \mathrm{M}$ Emo significantly increased the production of NETs compared with the LPS group $(P<0.05)($ Fig. 4c).

\section{Emo promotes phagocytosis of granulocytes}

Granulocytes were isolated and adjusted concentration to $1 \times 10^{6} / \mathrm{ml}$. After administration of LPS and Emo, granulocytes were co-cultured with pHrodo red E.coli and pHrodo green S.aureus for $30 \mathrm{~min}, 45 \mathrm{~min}$, and 60 $\mathrm{min}$. We found that the average fluorescence intensity of granulocytes phagocytosis of pHrodo green S.aureus increased from $2749.44 \pm 469.95$ at $30 \mathrm{~min}$ to $12,305.01 \pm$ 1425.02 at $60 \mathrm{~min}(P<0.01)$ (Fig. 5a). In addition, the average fluorescence intensity of granulocytes phagocytosis of pHrodo red E.coli increased from $4159.30 \pm$ 357.72 at $30 \mathrm{~min}$ to $7340.26 \pm 597.80$ at $60 \mathrm{~min}(P<0.01)$ (Fig. 5b). This result suggests that granulocytes phagocytosis of pHrodo green S.aureus and pHrodo red E.coli increases with time, reaching a peak at $60 \mathrm{~min}$. We also
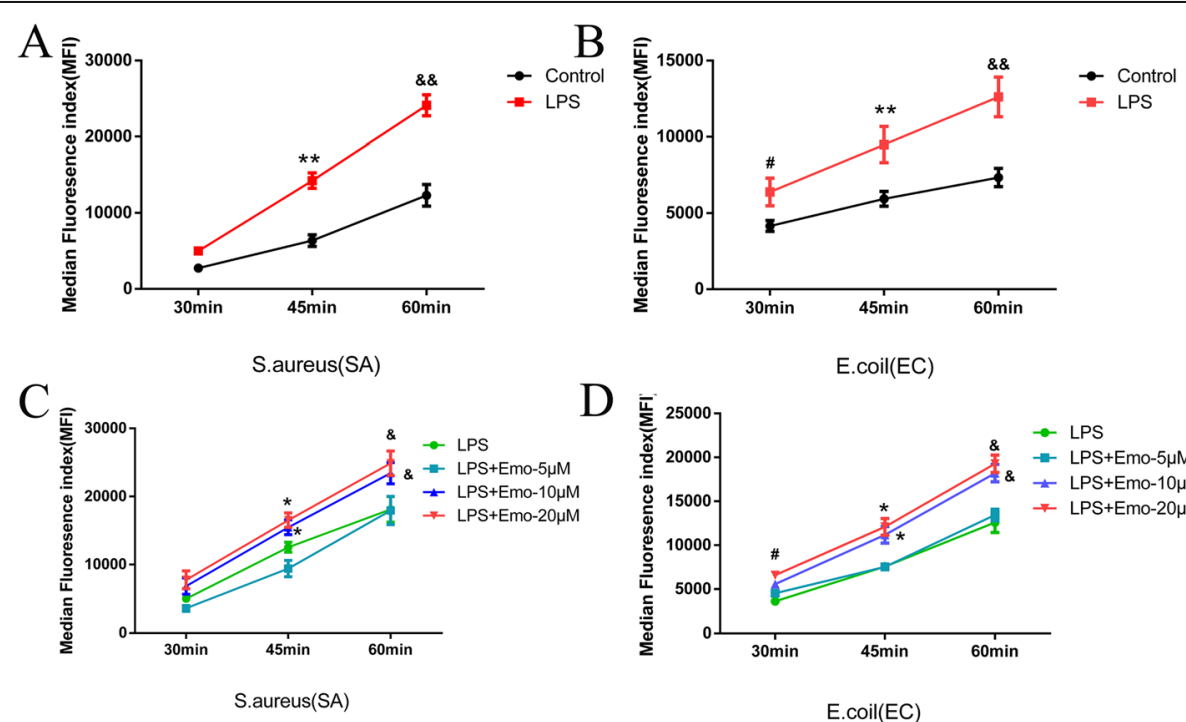

D

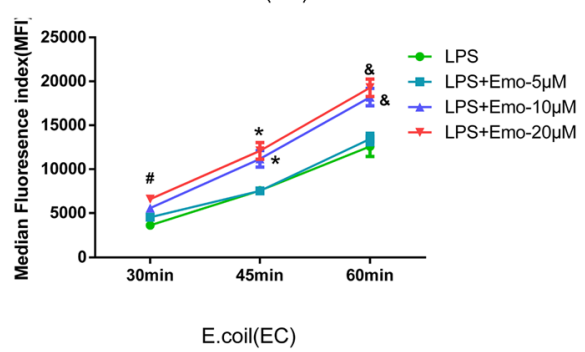

Fig. 5 Effect of Emo on phagocytosis of granulocytes. a The granulocyte phagocytosis of pHrodo Green S.aureus was tested with flow cytometry. b The granulocyte phagocytosis of pHrodo Red E.coli was tested with flow cytometry. The data are presented as the mean \pm SD. $\mathrm{n}=10$. ${ }^{\#} P<$ 0.05 versus LPS group in $30 \mathrm{~min}$; ${ }^{*} P<0.01$ versus LPS group in $45 \mathrm{~min}$; \& $P<0.01$ versus LPS group in 60 min. c Comparison of the phagocytosis of pHrodo Green S.aureus by granulocytes stimulated by Emo at different concentrations ( $5 \mu \mathrm{M}, 10 \mu \mathrm{M}$ and $20 \mu \mathrm{M})$.d Comparison of the phagocytosis of pHrodo Red E.coli by neutrophils stimulated by Emo at different concentrations $(5 \mu \mathrm{M}, 10 \mu \mathrm{M}$ and $20 \mu \mathrm{M})$. The data are presented as the mean \pm SD. $n=10 .{ }^{\#} P<0.05$ versus LPS group in 30 min; ${ }^{*} P<0.05$ versus LPS group in 45 min; ${ }^{\&} P<0.05$ versus LPS group in 60 min 
found that LPS-stimulated granulocytes showed increased phagocytosis of pHrodo green S.aureus compared with the control group at $45 \mathrm{~min}$ and $60 \mathrm{~min}(P<$ 0.01 ) (Fig. 5a). While the phagocytosis of granulocytes to pHrodo red E.coli at $30 \mathrm{~min}, 45 \mathrm{~min}$ and $60 \mathrm{~min}$ was higher than control group, especially at $60 \mathrm{~min}(P<0.05$ $\& P<0.01$ ) (Fig. 5b). In the groups treated with Emo, the experimental results showed that the granulocyte phagocytosis of pHrodo green S.aureus and pHrodo red E.coli at $45 \mathrm{~min}$ and $60 \mathrm{~min}$ was significantly enhanced for the $10 \mu \mathrm{M}$ and $20 \mu \mathrm{M}$ Emo groups $(P<0.05)$ (Fig. 5cd).

\section{Emo promotes apoptosis of granulocytes}

Granulocytes were isolated and adjusted concentration to $1 \times 10^{6} / \mathrm{ml}$. Granulocytes were treated with Emo $(5 \mu \mathrm{M}, 10 \mu \mathrm{M}$ and $20 \mu \mathrm{M})$ for $4 \mathrm{~h}$ and $24 \mathrm{~h}$. After labeling with Annexin V-FITC and SYTOX, the apoptosis of granulocytes was measured by flow cytometry (Fig. 6a). Our $4 \mathrm{~h}$ apoptosis experiment showed that apoptosis of cells did not increase significantly in the LPS group and the LPS + Emo $5 \mu \mathrm{M}$ group $(\mathrm{P}>0.05)$ (Fig. 6b). However, the apoptosis of cells increased significantly in the LPS + Emo $10 \mu \mathrm{M}$ group and the LPS + Emo $20 \mu \mathrm{M}$ group, when compared with the control group $(P<0.05)$ (Fig. $6 \mathrm{~b})$. We further compared the ratio of living cells, dead cells and necrotic cells between the LPS group and the LPS + Emo $20 \mu \mathrm{M}$ group, and found that there was no significant difference in the ratio of living cells, dead cells and necrotic cells between the two groups $(P>$ 0.05) (Fig. 6d). It suggests that Emo $10 \mu \mathrm{M}$ and Emo $20 \mu \mathrm{M}$ can promote the apoptosis of granulocytes following LPS stimulation.

The results of the $24 \mathrm{~h}$ apoptosis experiment are consistent with those of the $4 \mathrm{~h}$ experiment, confirming that $10 \mu \mathrm{M}$ Emo and $20 \mu \mathrm{M}$ Emo can promote apoptosis of cells following LPS stimulation at $24 \mathrm{~h}(P<0.05)$ (Fig. $6 c)$. Moreover, when compared with the LPS group, dead cells in the LPS + Emo $20 \mu \mathrm{M}$ group were significantly reduced $(P<0.05)$ (Fig. 6e). It suggests that $20 \mu \mathrm{M}$ Emo can not only promote the apoptosis of granulocytes following LPS stimulation but also reduce the ratio of dead granulocytes.

\section{Emo has no protective effect on the rat model of acute lung injury with granulocyte deficiency}

On the second day after receiving cyclophosphamide immunosuppression, the rats showed poor mental state, reduced diet and activity, gray and yellow hair, and the above performance was aggravated after injection of LPS.

From the H\&E staining samples of rat lung tissue, we can see that the lung histology of the control group is normal (Fig. 7a). In LPS group, the lung tissue injury was markedly damaged, with interstitial edema, hemorrhaging, thickening of the alveolar wall, and infiltration of inflammatory cells into the interstitium and alveolar spaces, as evidenced by an increase in lung injury score $(p<0.01)$. In LPS + Emo $20 \mu \mathrm{M}$ group, the histomorphology of lung tissue was similar to that of LPS, and the injury was severe (Fig. $7 \mathrm{~b}$ ). Emo could not reduce the concentration of TNF- $\alpha$ and IL- $1 \beta$ in lung tissue homogenate of LPS group. (Fig. 7C-D).

\section{Discussion}

Acute lung injury is a rapid non-cardiogenic bilateral lung infiltration syndrome characterized by alveolar vascular injury, granulocytes (mainly neutrophils) infiltration and accompanied by the release of proinflammatory factors [17]. Granulocytes and macrophages play an important role in the process of lung injury, in which granulocytes are the first line of defense against the invasion of pathogens. Macrophages play a key role in the subsequent clearance of apoptotic granulocytes and promoting the regression of inflammation. This study focuses on the effect of Emo on the function of neutrophils in ALI, so as to explore the antiinflammatory mechanism of Emo.

Granulocytes are the first line of defense against bacterial invasion and make up the largest proportion of leukocytes, which play a vital role in nonspecific immunity [18]. When the body is invaded by foreign microorganisms, granulocytes first gather at the inflammatory lesion site to play a defensive role. Emo (1,3,8-trihydroxy-6- methylanthraquinone) is a naturally occurring anthraquinone derivative and an active ingredient of some Chinese herbs. These herbs have been wildly used as traditional medicines in many countries, especially in eastern Asia. Currently, a number of researchers are focusing on the pharmacological effects of this compound. In the last 5 years, there have been many reports on the anti-tumor and anti-inflammatory effects of Emo [19, 20]. These pharmacological properties suggest that Emo might be a valuable therapeutic option for the prophylaxis and treatment of various diseases, including asthma, atopic dermatitis, osteoarthritis, diabetes and diabetic complications, atherosclerosis, Alzheimer's disease (AD), hepatic disease and several types of cancers such as pancreatic cancer, breast cancer, hepatocellular carcinoma and lung carcinoma.

In this study, we have identified a unique role for Emo related to the function of granulocytes in LPS-induced inflammatory lung injury. Our data clearly demonstrate that exogenous administration of Emo can reduce the lung injury score of ALI rats induced by LPS. Our experimental results also confirm that treatment with Emo inhibits plasma inflammatory cytokines, such as TNF- $\alpha$ and IL-1 $\beta$. Decreased plasma TNF- $\alpha$ and IL- $1 \beta$ levels in 


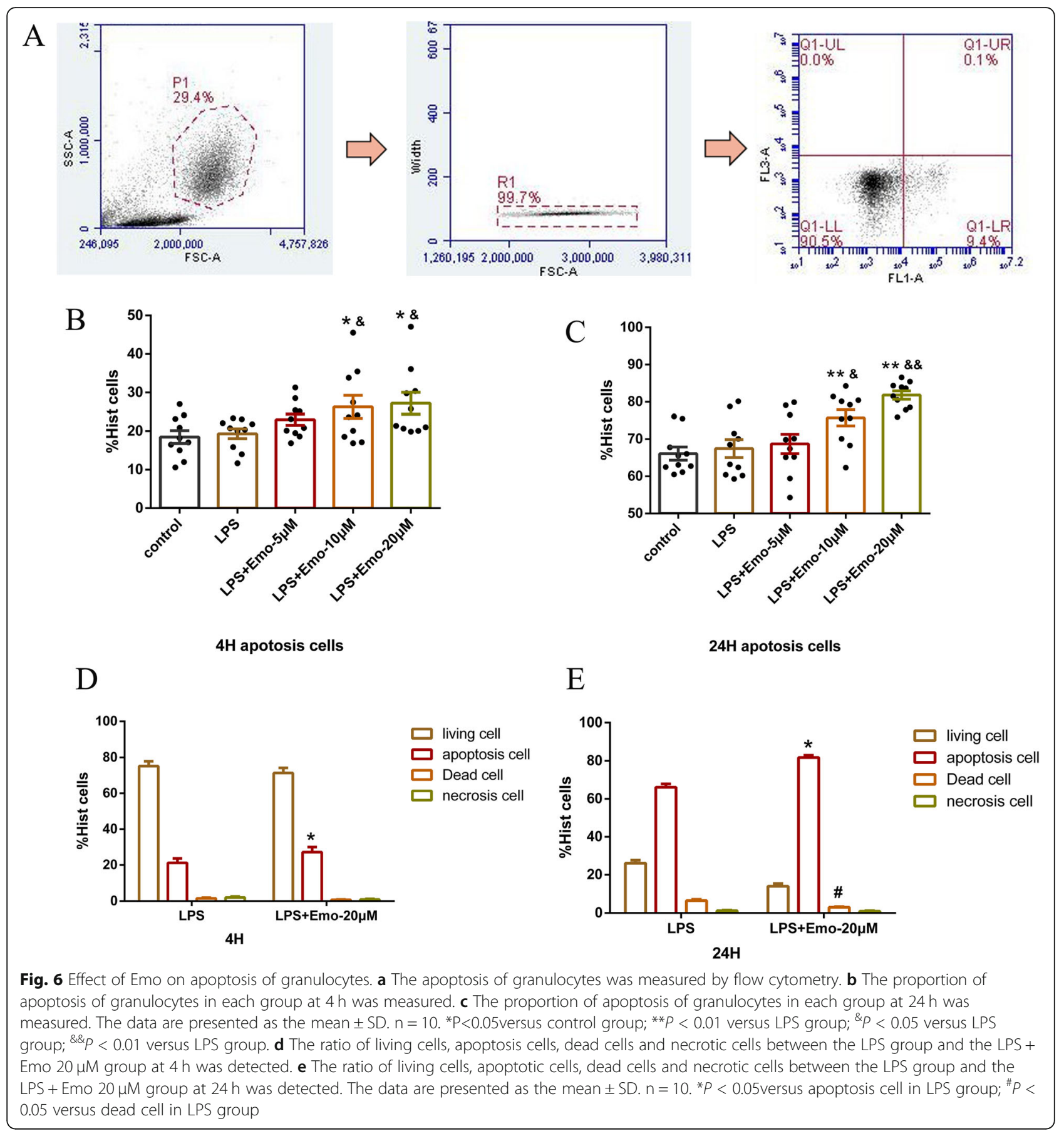

Emo-treated rats are consistent with the paradigm that Emo reduces the inflammatory response following ALI, in addition to ameliorating the severity of disease [21]. This suggests the potential of Emo as an effective lung protective therapeutic agent.

Neutrophils are over-activated during ALI, which releases neutrophil respiratory burst and ROS to damage the surrounding tissues. Priming of the neutrophil ROS production is believed to be involved in many inflammatory diseases, such as acute respiratory distress syndrome (ARDS), rheumatoid arthritis (RA), atherosclerosis, ischemia-induced tissue injury, hypertension, diabetes, kidney disease, and sepsis [22]. Our experimental results supported this conclusion. In this study, we evaluated the initiation of respiratory burst of suspended granulocytes in vitro using a SOD-inhibited cytochrome c reduction test, and luminol-amplified chemiluminescence to measure ROS [23]. SOD-inhibitable cytochrome $\mathrm{c}$ reduction assay is a standard technique for measuring superoxide dismutase production and has the 


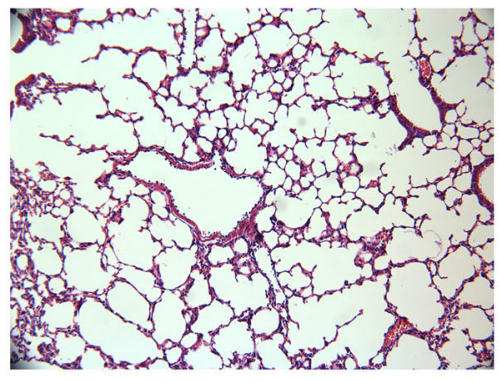

Control

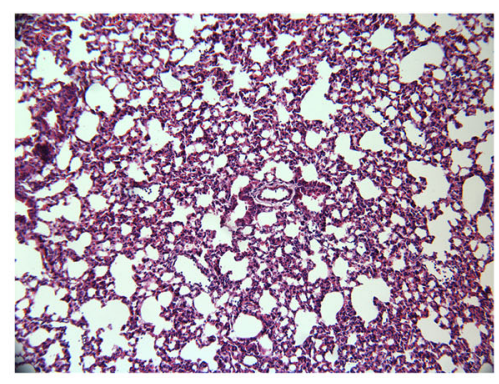

LPS

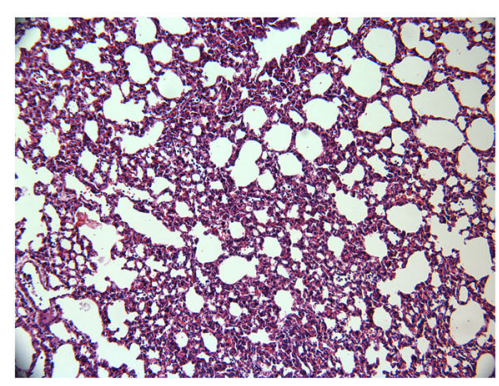

LPS+Emo20
B

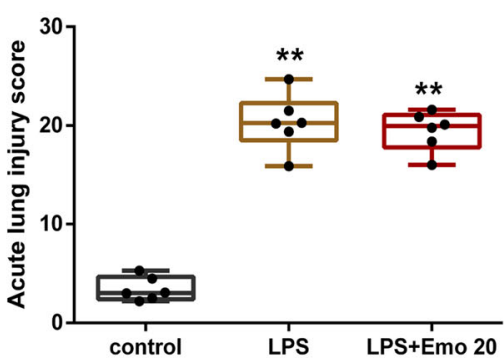

$\mathrm{C}$

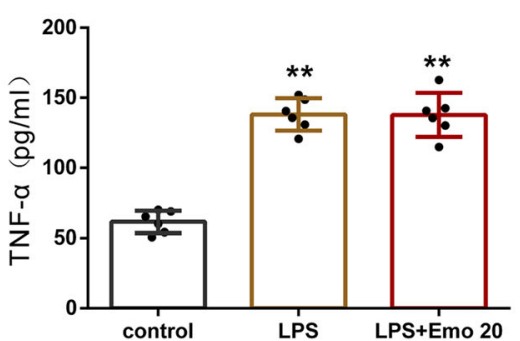

$\mathrm{D}$

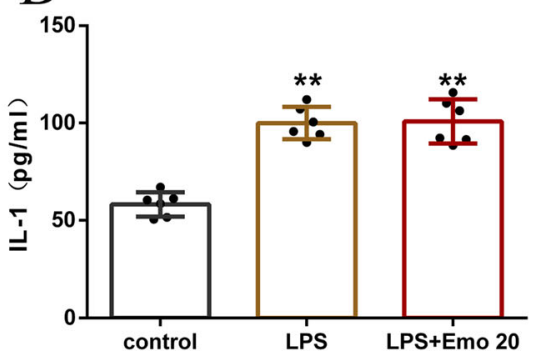

Fig. 7 Emo has no protective effect on the rat model of acute lung injury with granulocyte deficiency. a The lung tissues were obtained immediately after exsanguination ( $4 \mathrm{~h}$ after LPS), and the effect of Emo $20 \mathrm{mg} / \mathrm{kg}$ was assessed histologically in H\&E-stained sections (original magnification $\times 200$ ). $\mathbf{b}$ Lung injury scores. $\mathbf{c}$ The lung tissue homogenate TNF-a protein expression and $\mathbf{d}$ the lung tissue homogenate IL-1 $\beta$ protein expression. The data are presented as the mean \pm SD. $n=6$. ${ }^{* *} P<0.01$ versus control group

advantages of being a quantitative method that is specific for extracellular superoxide anions [24]. Luminolamplified chemiluminescence method has the advantages of being very sensitive and able to detect both extracellular and intracellular ROS. We found that Emo reduces granulocytes respiratory burst and ROS production in a dose-dependent manner, thus alleviating the damage from over-active granulocytes to surrounding tissues.

Elastase is a serine protease secreted by polymorphonuclear granulocytes, which plays an important role in many physiological and pathological processes such as the various inflammatory reactions, adult respiratory distress syndrome, and acute lung injury [25]. When exposed to various inflammatory factors, granulocytes release elastase via degranulation, which is then involved in the inflammatory response. Some studies believe that elastase is a destructive elastase that attacks the extracellular matrix and modulates inflammation and tissue remodeling. Its involvement may be direct (tissue damage) or indirect (proinflammatory or proapoptotic) [26-28]. However, it is undeniable that elastase is a necessary condition for neutrophil migration to inflammatory sites, and the proteolytic activity of elastase contributes to the body's defence against infectious agents by promoting the destruction of pathogenic bacteria [29-31]. Our results show that Emo at the concentration of $10 \mu \mathrm{M}$ and
$20 \mu \mathrm{M}$ can promote granulocytes elastase release induced by fMLP. To analyze the reasons, we consider that the time point selected in this study is $4 \mathrm{~h}$ after the successful establishment of acute lung injury model induced by LPS. This is the peak of inflammation and it is the time when a large number of granulocytes migrate to the inflammatory site. At this time, Emo promotes the release of granulocytes elastase is conducive to granulocyte migration to the site of inflammation to play a bactericidal function.

NETs are a kind of outer network structure, composed of complex three-reticular structure of DNA, and contains the main protein, elastase, myeloperoxidase (MPO), cathepsin G and other antibacterial proteases. It is a special bactericidal mechanism for neutrophils [8]. NETs are a double-edged sword in the inflammation process. Some studies have shown that a large number of extensive NETs formations can damage epithelial cells and endothelial cells, resulting in the spread of inflammation [32]. However, there are still a large number of studies that show that in the acute stages of inflammation, NETs not only capture microorganisms but also limit the diffusion of cytotoxic antimicrobial proteins and reduce host tissue damage [33, 34]. Our research results show that the production of NETs is higher than that of the control group following LPS stimulation of granulocytes, which indicates that the production of 
NETs is helpful in enabling granulocytes to play a bactericidal function in the acute stages of inflammation. Compared with the LPS group, $5 \mu \mathrm{M}$ Emo did not increase the generation of NETs, but $10 \mu \mathrm{M}$ Emo and $20 \mu \mathrm{M}$ Emo could significantly promote the generation of NETs. This data showed that Emo at concentrations of $10 \mu \mathrm{M}$ and $20 \mu \mathrm{M}$ could enhance the bactericidal ability of granulocytes by promoting the production of NETs.

During an inflammatory injury, granulocytes gather at the injury site to exert phagocytosis, an important granulocytes mechanism to kill pathogenic microorganisms. Our study found that Emo promotes phagocytosis of granulocytes: the phagocytosis of S.aureus and E.coli by neutrophils increases with time, reaching a peak at 60 $\mathrm{min}$. At $30 \mathrm{~min}, 45 \mathrm{~min}$ and $60 \mathrm{~min}$, the phagocytosis of S.aureus and E.coli by LPS-stimulated granulocytes was significantly stronger than the control group. We also found that while Emo $5 \mu \mathrm{M}$ did not promote the phagocytosis of granulocytes, $10 \mu \mathrm{M}$ Emo and $20 \mu \mathrm{M}$ Emo significantly promoted granulocyte phagocytosis of S.aureus and E.coli, indicating that Emo needs to reach a certain dose to promote granulocyte phagocytosis.

It is well known that granulocytes have a short life span, mainly due to apoptosis of granulocytes in the circulatory system over time. The resolution of an acute inflammatory response requires subsequent phagocytosis of apoptotic granulocytes by macrophages. Delayed apoptosis of activated granulocytes can lead to persistent acute lung inflammation and can eventually develop into one of the mechanisms of ARDS [35]. In this experiment, we mainly compared the effects of different doses of Emo on LPS-stimulated granulocyte apoptosis. We found that $5 \mu \mathrm{M}$ Emo had no effect on granulocyte apoptosis after $4 \mathrm{~h}$ and $24 \mathrm{~h}$ of treatment in the LPS group. However, $10 \mu \mathrm{M}$ Emo and $20 \mu \mathrm{M}$ Emo significantly promote the apoptosis of granulocytes in the LPS group after treating the granulocytes for $4 \mathrm{~h}$ and $24 \mathrm{~h}$ in a dose-dependent manner. This indicates that medium and large doses of Emo can promote the apoptosis of granulocytes and that the larger the dose, the better the effect. We have further compared the effects of $20 \mu \mathrm{M}$ Emo on dead cells and necrotic cells in the LPS group. The results show that $20 \mu \mathrm{M}$ Emo can only promote the apoptosis of granulocytes at $4 \mathrm{~h}$, but has no effect on dead cells and necrotic cells. However, at $24 \mathrm{~h}, 20 \mu \mathrm{M}$ Emo can not only promote the apoptosis of granulocytes but also reduce the number of dead granulocytes.

Finally, we used cyclophosphamide to inhibit circulating granulocytes in rats, and made a rat model of acute lung injury with granulocyte deficiency. The results showed that Emo could not reduce the pulmonary inflammatory infiltration and lung injury score in the rat model of acute lung injury with granulocyte deficiency, nor could it reduce the levels of inflammatory factors TNF- $\alpha$ and IL- $1 \beta$ in lung homogenate. It is further confirmed that Emo had a protective effect on ALI rats by affecting the function of granulocytes.

In summary, this study demonstrates that Emo alleviates lung injury and reduces the release of inflammatory cytokines in rats with acute lung injury induced by LPS, but has no protective effect on acute lung injury in rats with granulocytes deficiency. Moreover, Emo also downregulated neutrophil respiratory burst and the production of ROS in the LPS-stimulated granulocytes, thus reducing the damage of granulocytes to the surrounding tissues. Emo can also up-regulate the ability of granulocytes to phagocytize bacteria and generate NETs, thereby enhancing the bactericidal ability of granulocytes. In addition, Emo can promote the apoptosis of granulocytes and accelerate the resolution of inflammation. Interestingly, our research has confirmed that small doses of Emo have no obvious effect on granulocyte function. High-dose Emo also had obvious toxic effect on granulocytes. Only Emo (animal: $10-20 \mathrm{mg} / \mathrm{kg}$; cells: 10-20uM) had an obvious effect, and in this range in a dose-dependent manner. Our findings reveal a novel mechanism for Emo to attenuate the inflammatory reaction and shows that Emo could be exploited therapeutically for acute lung injury.

\section{Conclusion}

Emo has a protection effect on LPS-induced acute lung injury rats. It can alleviate lung injury and reduces the release of inflammatory cytokines, by affecting the various function of granulocytes. The appropriate dose (animal: $10-20 \mathrm{mg} / \mathrm{kg}$; cells: $10-20 \mu \mathrm{M}$ ) has the best effect.

\section{Materials and methods \\ Reagents}

LPS (Escherichia coli serotype 055:B5), formyl methionyl leucyl phenylalanine (fMLP), interleukin-8 (IL-8), phorbol ester (PMA), cell chromatography $\mathrm{C}$ (Cytochrome C), superoxide dismutase (SOD), Elastase, Hydroxyethylpiperazine Ethylsulfonic Acid (HEPES) and Emo were obtained from Sigma-Aldrich (St Louis, MO, USA). Tumor necrosis factor- $\alpha$ (TNF- $\alpha$ ) and interleukin-1 $\beta$ (IL-1 $\beta)$ ELISA kits were obtained from R\&D Systems (Minneapolis, MN). Anti-Myeloperoxidase (MPO) antibody (abcam, ab65871), MNase, RP-1 antibody (BD 550002), SYTOX Green, and Annexin V-FITC were obtained from eBioscience (San Diego, CA). pHrodo red $E$. coli (Cat.No.4615), pHrodo green S.aureus (Cat. No. 4620) were obtained from Sartorius (Göttingen, Germany). RPMI 1640, fetal bovine serum (FBS), trypsin, and enzyme-free cell dissociation buffer were purchased from Gibco (Grand Island, NY, USA). Penicillin and streptomycin in saline citrate buffer were from 
Invitrogen (Carlsbad, CA, USA). Other chemical reagents are of analytical grade.

\section{Animals, experimental procedure, and treatments}

Experiments were performed on adult male Sprague Dawley rats (250-300 g; Shanghai Experimental Animal Center of China). Rats were provided with water and food ad libitum. The use of animals in this study was approved by Animal Studies Ethics Committee of the Second Affiliated Hospital of Wenzhou Medical University.

Rats were randomized into five groups $(n=6)$ : control group, LPS group, LPS + Emo $5 \mathrm{mg} / \mathrm{kg}$ group, LPS + Emo10 mg/kg group and LPS + Emo $20 \mathrm{mg} / \mathrm{kg}$ group. In LPS group, rats received LPS $(20 \mathrm{mg} / \mathrm{kg})$ through the tail vein. LPS was dissolved in $0.9 \%$ normal saline. In the Emo group, rats received Emo $(5 \mathrm{mg} / \mathrm{kg}, 10 \mathrm{mg} / \mathrm{kg}$ and $20 \mathrm{mg} / \mathrm{kg}$ ) via intraperitoneal injection $30 \mathrm{~min}$ before LPS exposure. Emo was dissolved in 100\% DMSO at a concentration of $200 \mathrm{mg} / \mathrm{mL}$ and diluted in saline to the final concentration of $1 \mathrm{mg} / \mathrm{ml}$. The action time of LPSinduced acute lung injury in rats was $4 \mathrm{~h}$.

\section{Pathological studies}

Rats were anesthetized with chloral hydrate $(7 \mathrm{ml} / \mathrm{kg}$, intraperitoneally), intubated and connected to the animal ventilator (respiratory parameters are tidal volume: 10 $\mathrm{ml} / \mathrm{kg}$ and respiratory rate: $40-60 \mathrm{bpm}) 4 \mathrm{~h}$ after injection of LPS. After anesthesia and mechanical ventilation with pure oxygen for $1 \mathrm{~h}$, rats were killed by cutting off the abdominal aorta and bloodletting. Rats were subjected to thoracotomy and PBS $(25 \mathrm{ml} / \mathrm{min})$ was injected into the right ventricle to flush the pulmonary vessels. Finally, the right lower lung lobe of rats was cut and fixed in $4 \%$ paraformaldehyde for $24 \mathrm{~h}$ at room temperature, and $4 \mu \mathrm{m}$ sections were embedded in paraffin and stained with hematoxylin and eosin (H\&E) for light microscopy analysis. The rest of the lung tissue was frozen in liquid nitrogen for $48 \mathrm{~h}$ and stored in refrigerator at $-80^{\circ} \mathrm{C}$.

A semi-quantitative scoring system was adopted to evaluate lung injury, which included alveolar congestion, alveolar hemorrhaging, neutrophil infiltration or aggregation in the airspace or vessel wall, and alveolar wall/hyaline membrane thickness and inflammatory cell infiltration. The grading scale for the light microscopy pathologic findings was as follows: $0=$ no injury; 1 = slight injury (25\%); $2=$ moderate injury $(50 \%)$; $3=$ severe injury $(75 \%)$; and $4=$ very severe injury (almost $100 \%$ ). The results were graded from 0 to 4 for each item, as described previously. The four variables were summed to represent the lung injury score (total score: $0-16)$.
Determination of inflammatory cytokines in lung homogenate by enzyme-linked immunosorbent assay (ELISA)

Part of the right lung from individual rats was homogenized and centrifuged, and the levels of TNF- $\alpha$ and IL$1 \beta$ in the resulting tissue supernatants were determined using TNF- $\alpha$ and IL- $1 \beta$ ELISA kits.

After ultrasonic lysis of lung homogenate, the supernatant was obtained by centrifugation at $4{ }^{\circ} \mathrm{C}$ for $5000 \mathrm{r} /$ min for $15 \mathrm{~min}$. Follow the reagent instructions. $100 \mu \mathrm{l}$ of standard or sample to be tested was added to each hole, and the reaction plate was fully mixed and placed at $37^{\circ} \mathrm{C}$ for $30 \mathrm{~min}$. Wash the reaction plate fully with washing solution for 4 times and print it on the filter paper for 6 times. $100 \mu \mathrm{l}$ of enzyme-labeled antibody working solution was added to each well. Put the reaction plate at $37^{\circ} \mathrm{C}$ for $30 \mathrm{~min}$. The washing board is the same as before. $100 \mu \mathrm{l}$ of substrate working solution was added to each hole and reacted in the dark at $37^{\circ} \mathrm{C}$ for $15 \mathrm{~min}$. Add $100 \mu \mathrm{l}$ terminating liquid to each hole and mix well. The absorbance value of $450 \mathrm{~nm}$ was measured by enzyme labeling instrument within $30 \mathrm{~min}$.

\section{Separation and of rat granulocytes}

$20 \mathrm{ml}$ of heparinized fresh rat blood was treated with dextran to induce sedimentation of the red blood cells. Prepare a Percol gradient in a $15 \mathrm{ml}$ Falcon Tube by first pipetting $5 \mathrm{ml} 56 \%$ Percol, then put the sucker to the bottom of the tube, and slowly pipetting $2.5 \mathrm{ml} 80 \%$ Percol to the bottom. Then carefully draw up the plasma and white blood cell suspension from the blood sample with a pipette and slowly layer them on top of the Percol gradient $.4^{\circ} \mathrm{C}, 220 \mathrm{~g}$, centrifuge for $20 \mathrm{~min}$, accelerate to 1 , decelerate to 0 , remove the top layer of serum, suck out the granulocyte layer, add PBS to wash twice, the cells were resuscitated with RPMI-1640 medium containing 5\% FBS and then counted so that the cell concentration was $1 \times 10^{6} / \mathrm{ml}$.

Granulocytes were divided into five groups: control group, LPS group (100 ng/ml), LPS+ Emo $5 \mu \mathrm{M}$ group, LPS+ Emo $10 \mu \mathrm{M}$ group and LPS+ Emo $20 \mu \mathrm{M}$ group. Stimulation with Emo was performed for $30 \mathrm{~min}$ prior to LPS treatment.

\section{Immunofluorescence staining}

Granulocytes were isolated and adjusted concentration to $5 \times 10^{5} / \mathrm{ml}$. They were centrifuged for $5 \mathrm{~min}$ in order to fix the cells on glass slides and dried. Granulocytes were fixed with $4 \%$ paraformaldehyde at room temperature for $15 \mathrm{~min}$. Then they were permeabilize with $0.5 \%$ TritonX-100PBS for $20 \mathrm{~min}$ and blocked with blocking solution buffer for $30 \mathrm{~min}$. Granulocytes were incubated overnight at $4{ }^{\circ} \mathrm{C}$ with primary antibody (MPO antibody 1: 500), and then incubated the 
secondary antibody (1:200) onto glass slides for $1 \mathrm{~h}$ at room temperature in moist environmental box. DAPI was diluted into PBS in accordance with the instructions and added onto glass slides for $5 \mathrm{~min}$ at room temperature. $20 \mu \mathrm{L}$ of mounting medium was promptly added onto the slide, then put a cover slip on it, followed by mounting the coverslip with nail enamel. Finally, the slides were observed under a fluorescence microscope.

\section{Cell counting kit-8 (CCK8 assay)}

Granulocytes were isolated and adjusted concentration to $1 \times 10^{6} / \mathrm{ml}$. Granulocytes were added to 96 -well plate $(100 \mu 1$ per hole). Three multiple holes and blank control holes were set up at the same time (no cells). Emo was added into test wells as an inhibitor, which was divided into five concentration gradients of $5 \mu \mathrm{M}, 10 \mu \mathrm{M}$, $20 \mu \mathrm{M}, 40 \mu \mathrm{M}$ and $80 \mu \mathrm{M}$. PBS was used as negative control. After $4 \mathrm{~h}$ of Emo intervention, $10 \mu \mathrm{l}$ of CCK-8 reagent was added into each well. The plate was cultured in $5 \% \mathrm{CO}_{2}$ incubator at $37^{\circ} \mathrm{C}$ for $3 \mathrm{~h}$, the OD value of each well of wavelength $450 \mathrm{~nm}$ was detected by enzyme labeling instrument. Cell inhibition rate (IC) can be calculated according to the formula:

Cell inhibition rate $(\mathrm{IC})=[($ control group $\mathrm{OD}$ value - experimental group $\mathrm{OD}$ value $)$

/(control group OD value - zeroing group OD value $) \times] 100 \%$

\section{Respiratory burst detection}

The reactive oxygen species released by the activated inflammatory cells can reduce the membrane nonpenetrating cytochrome $\mathrm{C}$. The reduced cytochrome $\mathrm{C}$ has an absorption peak at $550 \mathrm{~nm}$. Therefore, the amount of reduced cytochrome $\mathrm{C}$ is measured using a spectrophotometer. The amount of active oxygen produced can be inferred from this data. (1)Set control group, LPS group and 3 Emo groups, and the appropriate amount of Emo was added in each group, $100 \mu \mathrm{l}$ of cytochrome $\mathrm{C}(1.5 \mathrm{mg} / \mathrm{ml})$ and $100 \mu \mathrm{l}$ neutrophils $(2 \times$ $\left.10^{7} / \mathrm{ml}\right)$ was then added; (2) $10 \mu \mathrm{l}$ SOD $(5000 \mathrm{U} / \mathrm{ml})$ was added, and the corresponding dose was added to the test group, equilibrated in a $5 \% \mathrm{CO}_{2}$ incubator at $37^{\circ} \mathrm{C}$ for $10 \mathrm{~min}$; (3) $10 \mu \mathrm{l}$ cytochalasin $\mathrm{B}(1 \mathrm{mmol} / \mathrm{L})$ was added to each group and after $3 \mathrm{~min}, 10 \mu \mathrm{l} \mathrm{fMLP}(0.1 \mathrm{mmol} / \mathrm{L})$ was added for a total of $1 \mathrm{ml}$ and each group was incubated in a $5 \% \mathrm{CO}_{2}$ incubator at $37^{\circ} \mathrm{C}$ for $30 \mathrm{~min}$; (4) Each group was removed and centrifuged at $2000 \mathrm{r} / \mathrm{min}$ for 10 min;(5) Supernatant was collected and the $\mathrm{OD}$ value was measured with a spectrophotometer. Since the production of $\mathrm{O}_{2}{ }^{-}$and the decrease in cytochrome $\mathrm{C}$ is in a 1:1 mol stoichiometric relationship, the yield of $\mathrm{O}_{2}{ }^{-}$is easily calculated. The millimolar extinction coefficient of the $1 \mathrm{~cm}$ optical path is 21.1, and the amount of $\mathrm{O}_{2}{ }^{-}$ produced by $2 \times 10^{6} / \mathrm{ml}$ of cells in $1 \mathrm{ml}$ of the solution with a diameter of $1 \mathrm{~cm}$ can be directly calculated according to the formula:

$$
\begin{aligned}
& \mathrm{OD} \times 47.4=\text { nmol O}_{\overline{2}} / 2 \times 106 \text { cells } / \text { time unit test group } \mathrm{O}_{\overline{2}} \text { inhibition rate } \\
& =\left(\text { control } \mathrm{O}_{\overline{2}} \text { content }- \text { test group } \mathrm{O}_{\overline{2}} \text { content }\right) / \text { control group } \mathrm{O}_{\overline{2}} \text { content } \times 100 \%
\end{aligned}
$$

\section{Elastase release assay}

The detection of granulocyte elastase release was mainly carried out by Elastase Activity Assay kit (ab204730). Five elastase solution test groups were prepared: Control group, LPS group, and Emo group (reaction solution concentration: $5 \mu \mathrm{M}, 10 \mu \mathrm{M}, 20 \mu \mathrm{M})$. (1)The isolated granulocytes were rinsed twice with PBS ( $\mathrm{pH}$ 7.4), the number of cells was adjusted to $1 \times 10^{7} / \mathrm{ml}, 500 \mu \mathrm{l}$ of solution was added to each group, and the corresponding drugs were added. Finally, each group was supplemented with PBS to $600 \mu \mathrm{l}$. The groups were pre-incubated for $30 \mathrm{~min}$ at $37^{\circ} \mathrm{C}$ in a $5 \% \mathrm{CO} 2$ incubator. In addition to Control group, $6 \mu \mathrm{l}$ of cytochalasin B $(1 \mathrm{mmol} / \mathrm{L})$ and LPS $(100 \mathrm{ng} / \mathrm{ml})$ was added to each group and cultured at $37^{\circ} \mathrm{C}$ in a $5 \% \mathrm{CO}_{2}$ incubator for $20 \mathrm{~min}$. The tubes were then placed in an ice-water bath to terminate the reaction. They were centrifuged at $1500 \mathrm{r} / \mathrm{min}$ for $5 \mathrm{~min}$, and the supernatant was dispensed and stored at $-80^{\circ} \mathrm{C}$ until use. (2)Elastase determination. Elastase standard was diluted with PBS: 50, 37.5, 25, 18.75, 12.5, 9.38, 6.25, $4.69,3.125$ series concentrations $(\mu \mathrm{g} / \mathrm{ml})$ and a PBS blank were used to generate a standard curve. Using a 96-well microtiter plate containing a standard or a $50 \mu \mathrm{l}$ sample to be tested, $100 \mu \mathrm{l}$ buffer was added (containing elastase substrate $1 \mathrm{mmol} / \mathrm{L}$, HEPES $0.1 \mathrm{~mol} / \mathrm{L}, \mathrm{NaCl} 0.5$ $\mathrm{mol} / \mathrm{L}, \mathrm{pH} 7.5)$. The OD value was read at $405 \mathrm{~nm}$ by a microplate reader (the emodin absorption is at $405 \mathrm{~nm}$ ), and then cultured at $37{ }^{\circ} \mathrm{C}$ in a $5 \% \mathrm{CO}_{2}$ incubator for $60 \mathrm{~min}$. The OD value at $405 \mathrm{~nm}$ was then read again, and the difference between the two OD values was recorded. The OD value of the substrate decomposes, and the elastase content is calculated according to the standard curve.

\section{Measuring NETs production}

Clear 96-well flat-bottomed plates were prepared, and $100 \mu \mathrm{l}$ of granulocytes were added to the relevant wells. Lipopolysaccharide (LPS, $100 \mathrm{ng} / \mathrm{ml}$ ), interleukin-8 (IL-8, $100 \mathrm{ng} / \mathrm{ml}$ ), phorbol ester (PMA, $1.5 \mathrm{ng} / \mathrm{ml}$ ) and Nformylthionyl-leucyl-phenylalanine (fMLP, $1000 \mathrm{ng} / \mathrm{ml}$ ) were used to treat the cells respectively. The control group was treated with an equal volume of medium. They were incubated for $3 \mathrm{~h}$ at $37^{\circ} \mathrm{C}$ in a $5 \% \mathrm{CO}_{2}$ incubator. SYTOX Green was diluted 1:500 (5 mM Stock; 1ul SYTOX Green into 499ul PBS), and then stored in the dark. $20 \mu \mathrm{l}$ of diluted SYTOX green was added to each well using a fresh tip for each well. $1 \mu \mathrm{l}$ of MNase 
was added to each well using a fresh tip for each well. They were then incubated at room temp for $10 \mathrm{~min}$ in the dark. Samples were transferred to $0.5 \mathrm{ml}$ microcentrifuge tubes without any pipetting of the liquid up and down. They were immediately centrifuged at 5000 $\mathrm{rpm}$ for $10 \mathrm{~min}$ in the micro-centrifuge before $160 \mu \mathrm{l}$ of the supernatant was removed and transferred to a black 96-well flat-bottomed plate. Fluorescence was measured immediately (programme: Gen5; excitation $485 \mathrm{~nm}$, emission $528 \mathrm{~nm}$ with optics position in top $50 \%$ of well with a 10-s 'medium' shake immediately prior to read).

\section{Measuring ROS production by isolated granulocytes}

Following isolation, cells were resuspended at $1 \times 106 / \mathrm{ml}$ in HBSS (with $\mathrm{Ca}^{2+}$ and $\mathrm{Mg}^{2+}$ ) $(4.5 \mathrm{ml}$ total) in $15 \mathrm{ml}$ Falcon. $100 \mu \mathrm{l}$ of granulocytes were added to each well of a 96-well plate. Cells were stimulated with Luminol (0.5 mM), IL-8(1.25 nM), fMLP $(2.5 \mu \mathrm{M})$, and PMA (25 $\mathrm{nM})$ for $1 \mathrm{~h}$. The luminometer was set up and the ROS level was tested on the instrument.

\section{Measuring the phagocytosis of granulocytes}

Granulocytes were isolated and adjusted concentration to $1 \times 10^{6} / \mathrm{ml}$. Following LPS and Emo treatment, granulocytes were inoculated into 96 -well plates at $100 \mu \mathrm{l} /$ well. pHrodo red E. coli and pHrodo green $S$. aureus were added to granulocytes respectively to stimulate granulocytes for $30 \mathrm{~min}, 45 \mathrm{~min}$, and $60 \mathrm{~min}$. Granulocytes were incubated at $37^{\circ} \mathrm{C}$ in a $5 \% \mathrm{CO}_{2}$ incubator in the dark, and then centrifuged at $250 \mathrm{~g}$ and $4{ }^{\circ} \mathrm{C}$ for $5 \mathrm{~min}$ to remove the supernatant. The cells were resuspended with $100 \mathrm{ul}$ of $2 \% \mathrm{PBS} / \mathrm{BSA}$, and this was repeated twice before the cell suspension from each well was transferred into flow tubes. $100 \mu \mathrm{l}$ of $2 \%$ PBS/BSA was added to each tube, gently mixed and placed on ice. Finally, the phagocytosis of granulocytes was measured using flow cytometry.

\section{Measuring the rate of apoptotic granulocytes}

Granulocytes were isolated and inoculated into six-well plates at an adjusted concentration of $1 \times 10^{6} / \mathrm{ml}$. The groups were divided into groups and treated for $4 \mathrm{~h}$ and $24 \mathrm{~h}$. Cells were harvested as normal and cells were transferred to the appropriate FACS tubes. They were centrifuged at $600 \mathrm{~g}$ for $4 \mathrm{~min}$ before the supernatant was poured off. Cells were resuspended in $200 \mu \mathrm{l}$ Annexin $\mathrm{V}$ buffer to wash the cells and then pelleted again. The cells were incubated in $100 \mu \mathrm{l}$ Annexin VFITC diluted 1:100 in Annexin V buffer for 15-20 min on ice and protected from the light. $200 \mu$ l Annexin V buffer was added to each tube. SYTOX was removed from the freezer and defrosted while being protected from the light. A SYTOX stock diluted 1:500 in Annexin $\mathrm{V}$ buffer was prepared. Immediately prior to running the sample on the CyAN, $30 \mu \mathrm{l}$ of the SYTOX solution was added to each tube and they were vortexed well to mix. The FITC and Violet 1 channels on the FACS machine were used to measure.

\section{To establish a rat model of acute lung injury with granulocyte deficiency}

Cyclophosphamide (CTX) is a kind of non-specific chemotherapeutic drug in cell cycle, which is widely used in clinic. It can kill the cells in each phase of the proliferation cycle and inhibit the number of leukocytes in bone marrow.

In this experiment, rats were injected intraperitoneally with cyclophosphamide $(75 \mathrm{mg} / \mathrm{kg}) 4$ days before and 1 day before the acute lung injury induced by LPS. And 1 day before the acute lung injury model was prepared and 1 day after the model was prepared, the number of granulocytes in rat tail vein blood was less than $2 \times 10^{5}$ / $\mathrm{ml}$ by using the blood cell count version technology, Therefore, the rat model of acute lung injury with granulocytedeficiency was successfully prepared.

\section{Statistical analysis}

The data represent the mean \pm SD. There were no missing, lost, or excluded data. Based on previous experience, no prior power analysis was conducted; all data were analyzed by one-way ANOVA followed by Tukey's posthoc test for multiple comparisons. All tests were twosided, and significance was determined at the $p<0.05$ level. Statistical analyses were performed using Prism 6.0 software (GraphPad Software, San Diego, CA).

\section{Abbreviations}

ALI: Acute lung injury; ARDS: acute respiratory distress syndrome;

Emo: Emodin; LPS: lipopolysaccharide; TNF-a: tumor necrosis factor-a; IL$1 \beta$ : Interleukin-1 $\beta$; NETs: neutrophil extracellular traps; ROS: reactive oxygen species; fMLP: formyl methionyl leucyl phenylalanine; IL-8: interleukin-8; PMA: phorbol ester; Cytochrome C: cell chromatography C; SOD: superoxide dismutase; HEPES: Hydroxyethylpiperazine Ethylsulfonic Acid; FBS: fetal bovine serum; ELISA: enzyme-linked immunosorbent assay; CCK8: Cell Counting Kit-8; CTX: Cyclophosphamide; MPO: myeloperoxidase;

RA: rheumatoid arthritis

\section{Acknowledgements}

We are highly thankful to Dr. Zi Wang and Dr. Shuai Hu for assistance with technical assistance.

\section{Authors' contributions}

Hongxia Mei performed the experiments and Ying Tao collected the raw data. Tianhao Zhang performed the statistical analysis and Feng Qi drafted the manuscript. All authors contributed towards data analysis, drafting and critically revising the paper and agree to be accountable for all aspects of the work.

\section{Funding}

This study was supported by the National Natural Science Foundation of China (No. 81672250), Zhejiang Natural Science Foundation (NO. LQ15H010002) and Project of Wenzhou Science and Technology Bureau(Y20140084). 


\section{Availability of data and materials}

All data generated or analyzed during this study are included in this published article and are available from the corresponding author upon request.

\section{Ethics approval and consent to participate}

All animals received care in compliance with the Principles of Laboratory Animal Care and National standards.

\section{Consent for publication}

Not applicable.

\section{Competing interests}

The authors declare that they have no competing interests.

\section{Author details}

'Department of Anesthesiology, Qilu Hospital, Cheeloo College of Medicine, Shandong University, Jinan 250012, Shandong Province, China. ${ }^{2}$ Department of Anesthesiology, The Second Affiliated Hospital and Yuying Children's Hospital of Wenzhou Medical University, Wenzhou 325000, Zhejiang Province, China.

Received: 23 January 2020 Accepted: 30 July 2020

Published online: 08 August 2020

\section{References}

1. Sweeney RM, McAuley DF. Acute respiratory distress syndrome. Lancet. 2016;388(10058):2416-30

2. Hamid U, Krasnodembskaya A, Fitzgerald M, Shyamsundar M, Kissenpfennig A, Scott C, Lefrancais E, Looney MR, Verghis R, Scott J, Simpson AJ, McNamee J, McAuley DF, O'Kane CM. Aspirin reduces lipopolysaccharideinduced pulmonary inflammation in human models of ARDS. Thorax. 2017; 72(11):971-80.

3. Haohao Dong XTZZ. Structural insight into lipopolysaccharide transport from the gram-negative bacterial inner membrane to the outer membrane. Biochim Biophys Acta Mol Cell Biol Lipids. 2017;11(1862):1461-7.

4. Nourshargh S, Alon R. Leukocyte migration into inflamed tissues. Immunity. 2014;41(5):694-707.

5. Vestweber D. How leukocytes cross the vascular endothelium. Nat Rev Immunol. 2015;15(11):692-704.

6. Nathan C. Neutrophils and immunity: challenges and opportunities. Nat Rev Immunol. 2006;6(3):173-82.

7. Sollberger G, Tilley DO, Zychlinsky A. Neutrophil extracellular traps: the biology of chromatin externalization. Dev Cell. 2018;44(5):542-53.

8. Papayannopoulos V. Neutrophil extracellular traps in immunity and disease. Nat Rev Immunol. 2018;18(2):134-47.

9. Liu S, Yue Y, Pan P, Zhang L, Su X, Li H, Li H, Li Y, Dai M, Li Q, Mao Z. IRF-1 intervention in the classical ROS-dependent release of NETs during LPSinduced acute lung injury in mice. Inflammation. 2019;42(1):387-403.

10. Greenlee Wacker MC. Clearance of apoptotic neutrophils and resolution of inflammation. Immunol Rev. 2016;273(1):357-70.

11. Stark MA, Huo Y, Burcin TL, Morris MA, Olson TS, Ley K. Phagocytosis of apoptotic neutrophils regulates Granulopoiesis via IL-23 and IL-17. Immunity. 2005;22(3):285-94.

12. Li D, Shao X, Wu J, Yi XX. Noise-induced distributed entanglement in atomcavity-fiber system. Opt Express. 2017;25(26):33359.

13. Nathan C. Points of control in inflammation. Nature. 2002;420(6917):846-52.

14. Morimoto K, Nishimura K, Miyasaka S, Maeta H, Taniguchi I. The effect of Sivelestat sodium hydrate on severe respiratory failure after thoracic aortic surgery with deep hypothermia. Ann Thorac Cardiovas. 2011;17(4):369-75.

15. Wei $W$, Lin $S$, Liu D, Wang Z. The distinct mechanisms of the antitumor activity of emodin in different types of cancer (review). Oncol Rep. 2013; 30(6):2555-62.

16. Shrimali D, Shanmugam MK, Kumar AP, Zhang J, Tan BKH, Ahn KS, Sethi G. Targeted abrogation of diverse signal transduction cascades by emodin for the treatment of inflammatory disorders and cancer. Cancer Lett. 2013; 341(2):139-49.

17. Laffey JG, Misak C, Kavanagh BP. Acute respiratory distress syndrome. BMJ. 2017;359:5055.

18. Liew PX, Kubes P. The Neutrophil's role during health and disease. Physiol Rev. 2019;99(2):1223-48.
19. Chen Y, Xu Y, Zhang H, Yin J, Fan X, Liu D, Fu H, Wan B. Emodin alleviates jejunum injury in rats with sepsis by inhibiting inflammation response. Biomed Pharmacother. 2016;84:1001-7.

20. Liu C. Inhibition of mechanical stress-induced hypertrophic scar inflammation by emodin. Mol Med Rep. 2015;11(6):4087-92.

21. Dong X, Fu J, Yin X, Cao S, Li X, Lin L, Ni J. Emodin: a review of its pharmacology. Toxicity Pharmacokinetics Phytother Res. 2016;30(8):1207-18.

22. El Benna J, Hurtado Nedelec M, Marzaioli V, Marie JC, Gougerot Pocidalo MA, Dang PMC. Priming of the neutrophil respiratory burst: role in host defense and inflammation. Immunol Rev. 2016;273(1):180-93.

23. Hurtado-Nedelec M, Makni-Maalej K, Gougerot-Pocidalo M, Dang PM, ElBenna J. Assessment of priming of the human neutrophil respiratory burst. Methods Mole Biol (Clifton, N.J.). 2014;1124:405.

24. Nauseef WM. Identification and quantitation of superoxide anion: essential steps in elucidation of the phagocyte "respiratory burst". J Immunol. 2014; 193(11):5357-8

25. Korkmaz B, Moreau T, Gauthier F. Neutrophil elastase, proteinase 3 and cathepsin G: physicochemical properties, activity and physiopathological functions. Biochimie. 2008;90(2):227-42.

26. Meyer-Hoffert U, Wiedow O. Neutrophil serine proteases: mediators of innate immune responses. Curr Opin Hematol. 2011;18(1):19-24.

27. Muley MM, Krustev E, Reid AR, McDougall JJ. Prophylactic inhibition of neutrophil elastase prevents the development of chronic neuropathic pain in osteoarthritic mice. J Neuroinflamm. 2017:14(1):168.

28. Polverino E, Rosales-Mayor E, Dale GE, Dembowsky K, Torres A. The role of neutrophil Elastase inhibitors in lung diseases. Chest. 2017;152(2):249-62.

29. González-Fernández E, Staderini M, Yussof A, Scholefield E, Murray AF, Mount AR, Bradley M. Electrochemical sensing of human neutrophil elastase and polymorphonuclear neutrophil activity. Biosens Bioelectron. 2018;119: 209-14.

30. Kumar H, Choi H, Jo M, Joshi HP, Muttigi M, Bonanomi D, Kim SB, Ban E, Kim A, Lee S, Kim K, Sohn S, Zeng X, Han I. Neutrophil elastase inhibition effectively rescued angiopoietin-1 decrease and inhibits glial scar after spinal cord injury. Acta Neuropathol Commun. 2018;6(1):73.

31. Korkmaz B, Horwitz MS, Jenne DE, Gauthier F. Neutrophil Elastase, proteinase 3, and CathepsinG as therapeutic targets in human diseases. Pharmacol Rev. 2010:62(4):726-59.

32. Branzk N, Lubojemska A, Hardison SE, Wang Q, Gutierrez MG, Brown GD, Papayannopoulos V. Neutrophils sense microbe size and selectively release neutrophil extracellular traps in response to large pathogens. Nat Immunol. 2014;15(11):1017-25.

33. Brinkmann VZA. Beneficial suicide: why neutrophils die to make NETs. Nat Rev Microbiol. 2017;8(5):577-82.

34. Hahn J, Knopf J, Maueroder C, Kienhofer D, Leppkes M, Herrmann M. Neutrophils and neutrophil extracellular traps orchestrate initiation and resolution of inflammation. Clin Exp Rheumatol. 2016;34(4 Suppl 98):6-8

35. Jiang C. LZHR. Inactivation of Rab11a GTPase in macrophages facilitates phagocytosis of apoptotic neutrophils. J Immunol. 2017;198(4):1660-72.

\section{Publisher's Note}

Springer Nature remains neutral with regard to jurisdictional claims in published maps and institutional affiliations.

Ready to submit your research? Choose BMC and benefit from:

- fast, convenient online submission

- thorough peer review by experienced researchers in your field

- rapid publication on acceptance

- support for research data, including large and complex data types

- gold Open Access which fosters wider collaboration and increased citations

- maximum visibility for your research: over $100 \mathrm{M}$ website views per year

At $\mathrm{BMC}$, research is always in progress.

Learn more biomedcentral.com/submission 